\title{
Long-term effect of early postnatal overnutrition on insulin resistance and serum fatty acid profiles in male rats
}

Fei Bei ${ }^{1,2,3}$, Jia Jia ${ }^{4}$, Yi-Qun Jia ${ }^{5}$, Jian-Hua Sun ${ }^{6}$, Fei Liang ${ }^{6}$, Zhong-Yi Yu ${ }^{7}$ and Wei Cai ${ }^{1,2,3^{*}}$

\begin{abstract}
Background: Increasing evidence suggests that overnutrition during the early postnatal period, a critical window of development, increases the risk of adult-onset obesity and insulin resistance. In this study, we investigated the impact of overnutrition during the suckling period on body weight, serum biochemistry and serum fatty acid metabolomics in male rats.

Methods: Rats raised in small litters (SL, 3 pups/dam) and normal litters (NL, 10 pups/dam) were used to model early postnatal overnutrition and control, respectively. Serum glucose, triglyceride, high-density lipoprotein-cholesterol, free fatty acid, insulin and leptin concentrations were assayed using standard biochemical techniques. Serum fatty acids were identified and quantified using a gas chromatography-mass spectrometry-based metabolomic approach. mRNA and protein levels of key components of the insulin receptor signaling pathway were measured in epididymal fat and gastrocnemius muscle by quantitative PCR and western blotting.

Results: SL rats were $37.3 \%$ and $15.1 \%$ heavier than NL rats at weaning and 16-weeks-old, respectively. They had increased visceral fat mass, adult-onset insulin resistance and glucose intolerance as well as elevated serum levels of free fatty acids and triglycerides. All detectable fatty acids were elevated in the serum of SL pups at weaning compared to NL controls, and significant increases in the levels of four fatty acids (palmitic acid, palmitoleic acid, oleic acid and arachidonic acid) persisted into adulthood. Moreover, a significantly positive correlation was identified between an insulin resistance index (HOMA-IR) and concentrations of myristic, palmitic, palmitoleic and oleic acid in serum at postnatal 16 weeks. Early postnatal overnutrition also resulted in a significant downregulation of insulin receptor substrate-1 (Irs-1), protein kinase B (Akt2) and glucose transporter 4 (Glut4) at the protein level in epididymal fat of SL rats at 16 weeks, accompanied by decreased mRNA levels for Irs-1 and Glut4. In gastrocnemius muscle, Akt2 and Glut4 mRNA and Glut4 protein levels were significantly decreased in SL rats.
\end{abstract}

Conclusions: This study demonstrates that early postnatal overnutrition can have long-lasting effects on body weight and serum fatty acid profiles and can lead to impaired insulin signaling pathway in visceral white adipose tissue and skeletal muscle, which may play a major role in IR.

Keywords: Early overnutrition, Insulin resistance, Insulin receptor substrate 1, Glucose transporter 4, Fatty acid

\footnotetext{
*Correspondence: caiw1978@163.com

'Xin Hua Hospital, Shanghai Jiao Tong University School of Medicine, 1665

Kongjiang Road, Shanghai 200092, China

${ }^{2}$ Shanghai Key Laboratory of Pediatric Gastroenterology and Nutrition, 1665

Kongjiang Road, Shanghai 200092, China

Full list of author information is available at the end of the article
} 


\section{Introduction}

The dramatic increase in the prevalence of obesity in recent years is a global health problem because it significantly increases the risk of adult-onset metabolic diseases such as glucose intolerance, insulin resistance (IR), Type 2 diabetes and cardiovascular disorders. In China, the overall prevalence of diabetes and prediabetes in adults has been estimated at 113.9 million and 493.4 million, respectively, in 2013 [1]. Insulin resistance (IR) plays a pivotal role in the development of metabolic diseases [2]. In addition to causing the excessive energy intake in developed countries, it has been recognized that nutrient availability during early postnatal life has an important influence on obesity, IR and resulting adult health [3-5]. In rodents, early postnatal overnutrition can be induced by a reduction of the number of pups per dam from 1012 (normal litter, NL) to 3-4 (small litter, SL), resulting an increased intake of calories and fat. Rats or mice raised in SL develop a "metabolic-syndrome-like" phenotype in adulthood including overweight, obesity, IR, hyperinsulinemia and heperleptinemia [6-8]. The SL model has thus been widely used to investigate the long-term consequences of neonatal overnutrition and the molecular mechanisms underlying these events.

Insulin plays a primary role in the regulation of total body glucose homeostasis by increasing glucose uptake in muscle and adipose tissue, and inhibiting glucose production in the liver. Insulin-dependent glucose uptake occurs in skeletal muscle and adipose tissue via the insulin receptor signaling pathway. Insulin binding to the $\alpha$ subunit of the insulin receptor leads to phosphorylation of insulin receptor substrate (IRS) proteins and the subsequent activation of phosphatidyl 3-kinase/protein kinase B (Akt2), which results in translocation of the glucose transporter 4 (GLUT4) from storage vesicles to the plasma membrane and stimulation of glucose uptake [9]. Decreased expression of any of the main components of this pathway such as IRS, Akt2 and GLUT4 may contribute to glucose intolerance, IR and type 2 diabetes. In particular, GLUT4 in muscle and adipose tissue is essential for normal global glucose homeostasis. Studies have demonstrated that heterozygous GLUT4+/mice which exhibit decreased GLUT4 protein in muscle and adipose tissue display IR and a tendency toward diabetes that is consistent with a major role of GLUT4 in glucose disposal [10-12].

Studies have suggested that increased circulating concentrations of individual fatty acids may be implicated in causing IR in humans [13-15]. Using metabolomics, a promising method of identifying biomarkers of shortand long-term physiological or pathological changes in the organism [16], a number of specific lipids have been suggested as potential biomarkers for IR in humans. Some of these are involved in causing IR by interfering with the insulin receptor signaling pathway [14, 17]. In this study, we employed a metabolomic approach to identify and quantify individual fatty acids in the serum of SL and NL rats both at weaning and during adulthood. We further examined the expressions of main components of the insulin receptor signaling pathway in visceral adipose tissues and skeletal muscle of adult rats to determine whether blunting of the insulin signaling pathway in these tissues may also contribute to IR.

\section{Results}

\section{Effect of early postnatal overnutrition on body weight during development}

To investigate the effect of postnatal overnutrition on body weight, we adjusted litter sizes on postnatal day 2 to either ten male pups/dam (normal litter, NL) or three male pups/dam (small litter, SL) and monitored body weight over the first 16 weeks of life. NL and SL pups had the same average body weight at the time of litter adjustment, but SL pups gained weight more rapidly and were already significantly heavier at postnatal day 7 (Fig. 1a). At weaning (postnatal day 21), SL pups were

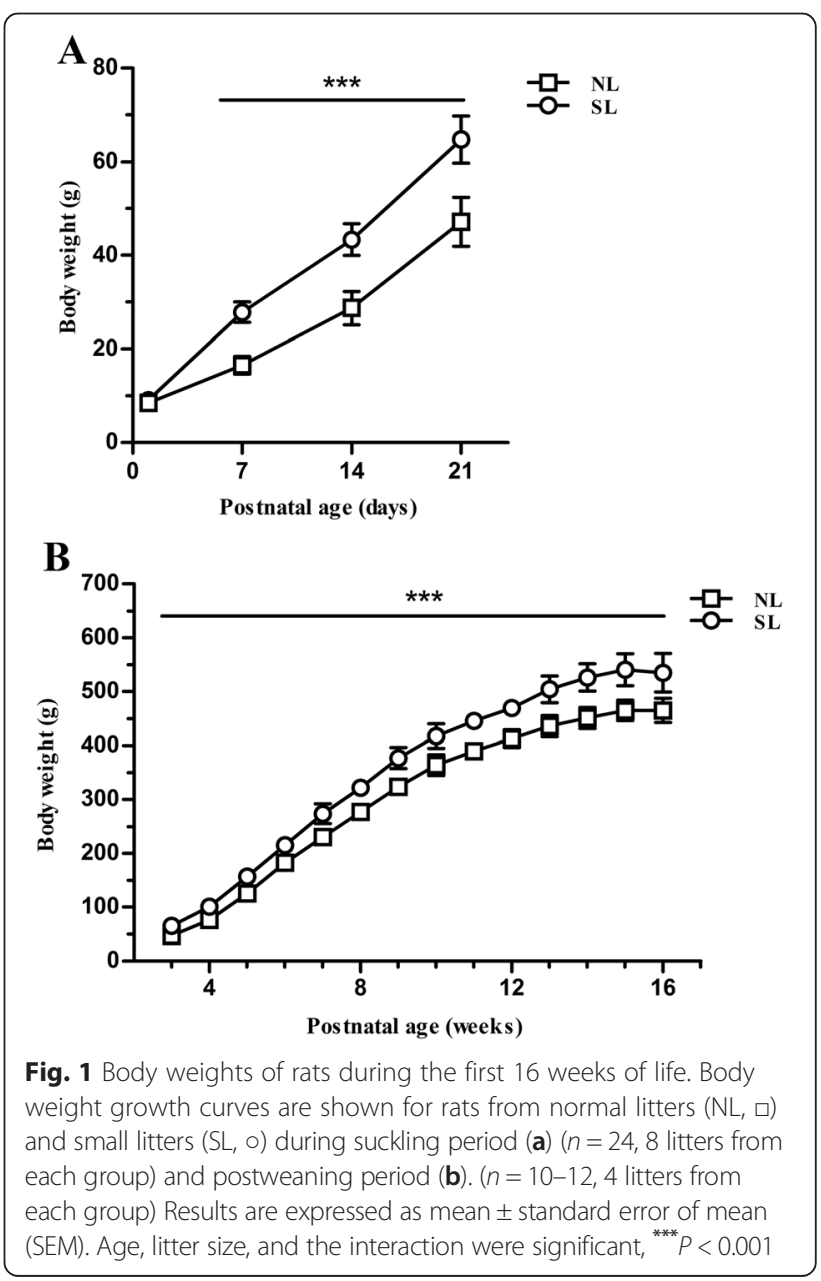


$37.3 \%$ heavier than NL pups (64.8 g vs. $47.2 \mathrm{~g}$ ), and this significant difference in body weight between the two groups persisted into adulthood (Fig. 1b). At the age of 16 weeks, SL rats were $15.1 \%$ heavier than NL rats (534.8 g vs. $464.8 \mathrm{~g})$.

\section{Food intake, organ weights and metabolic parameters in} the NL and SL groups

To further characterize the effects of early postnatal overnutrition in adulthood, rats were killed at 16 weeks and their livers, hindlimb gastrocnemius muscles, epididymal fat pads and perirenal fat pads were harvested and weighed. Liver, gastrocnemius and epidiymal fat pads were all significantly heavier in rats raised in SL compared with NL; however after normalization for body weight only the epididymal fat pads were significantly heavier in the SL rats (Table 1). Furthermore, serum from 16-week-old SL rats was found to contain significantly higher levels of triglycerides and free fatty acids compared to NL rats. There were no differences in the serum leptin and the density lipoprotein-cholesterol (HDL-C) concentrations between the two groups (Table 2).

\section{Serum levels of fasting glucose and insulin}

A commonly used estimate of insulin resistance is the homeostasis model assessment-insulin resistance index (HOMA-IR), which is proportional to the product of serum glucose and insulin levels in fasted animals. We found that glucose levels were significantly higher in the serum of fasted SL pups than NL pups at 3 weeks of age, but the groups did not differ after weaning (Fig. 2a). By contrast, significantly elevated serum insulin concentrations were observed in SL rats at 16 weeks of age, but not before (Fig. 2b). At 16 weeks the HOMA-IR index was significantly higher in SL rats compared with NL

Table 1 Food intake, and body and organ weights in 16 week old rats

\begin{tabular}{lll}
\hline & $\mathrm{NL}(n=10)$ & $\mathrm{SL}(n=10)$ \\
\hline Food intak (g/d) & $28.67 \pm 2.07$ & $29.83 \pm 2.32$ \\
Body weight (BW) (g) & $464.8 \pm 22.4$ & $534.8 \pm 35.8^{* * *}$ \\
Organ weights & \\
Liver (g) & $11.4 \pm 0.8$ & $13.0 \pm 1.0^{* *}$ \\
Epididymal fat pad (g) & $6.1 \pm 1.0$ & $8.5 \pm 1.8^{* *}$ \\
Perirenal fat pad (g) & $10.9 \pm 2.9$ & $13.0 \pm 2.7$ \\
Gastrocnemius (g) & $5.9 \pm 0.4$ & $6.4 \pm 0.3^{* *}$ \\
Liver/BW (\%) & $2.33 \pm 0.16$ & $2.43 \pm 0.12$ \\
Epididymal fat/BW (\%) & $1.24 \pm 0.14$ & $1.58 \pm 0.28^{*}$ \\
Perirenal fat/BW (\%) & $2.20 \pm 0.48$ & $2.42 \pm 0.43$ \\
Gastrocnemius/BW (\%) & $1.20 \pm 0.04$ & $1.21 \pm 0.07$ \\
\hline
\end{tabular}

Values are mean \pm S.E.M. ( $n=10,4$ litters from each group). NL: normal litter; SL: small litter, ${ }^{*} P<0.05,{ }^{* * *} P<0.01,{ }^{* * *} P<0.001$
Table 2 Blood serum biochemistry in 16 week old rats from normal and small litters

\begin{tabular}{lll}
\hline & $\mathrm{NL}(n=6)$ & $\mathrm{SL}(n=6)$ \\
\hline $\mathrm{TG}(\mathrm{mmol} / \mathrm{L})$ & $0.93 \pm 0.26$ & $1.39 \pm 0.41^{*}$ \\
$\mathrm{HDL}-\mathrm{C}(\mathrm{mmol} / \mathrm{L})$ & $0.52 \pm 0.09$ & $0.51 \pm 0.05$ \\
$\mathrm{FFA}(\mathrm{mmol} / \mathrm{L})$ & $0.34 \pm 0.04$ & $0.41 \pm 0.05^{* *}$ \\
Leptin $(\mathrm{pg} / \mathrm{ml})$ & $7.28 \pm 1.61$ & $8.3 \pm 3.6$ \\
\hline
\end{tabular}

Values are mean \pm S.E.M. $(n=6,4$ litters from each group) NL: normal litter; $S L$ : small litter; TG: triglyceride; HDL-C: high density lipoprotein cholesterol; FFA: free fatty acid. ${ }^{*} P<0.05,{ }^{* *} P<0.01$

rats, indicating the development of insulin resistance (Fig. 2c).

Early postnatal overnutrition induces glucose intolerance To further investigate insulin resistance in SL and NL rats, we performed an intraperitoneal glucose tolerance test (IPGTT) at 6 and 14 weeks of age. Rats were given an intraperitoneal glucose load, then blood glucose levels were measured at regular intervals to monitor their return to baseline over a two hour period. At 6 weeks of age, there was no difference in blood glucose levels between the two groups at any timepoint (Fig. 3a). However, at 14 weeks of age, SL rats had significantly higher serum glucose levels at $60 \mathrm{~min}$ and a significantly increased area under the curve (AUC) when compared to $\mathrm{NL}$ rats (Fig. 3b, c), indicating that early postnatal overnutrition induces glucose intolerance in adult rats. The glucose intolerance observed in adult SL rats indicates an imbalance between insulin production and action in these animals due to decreased insulin secretion from pancreatic island $\beta$ cells and/or decreased insulin sensitivity in target organs.

\section{Effect of early postnatal overnutrition on mRNA expression and protein levels for components of insulin signaling pathway from skeletal muscle and visceral adipose tissue}

Insulin resistance may arise from downregulation of key components of the insulin signaling pathway. To investigate whether this was the case following postnatal overnutrition, the levels of three such proteins, Irs-1, Akt2 and Glut4, were measured by western blotting in lysates from epididymal fat and gastrocnemius muscle isolated from SL and NL rats at 16 weeks of age. A significant decrease in expression of all of the above proteins was observed in the epididymal fat of SL rats compared to NL controls $(P<0.05)$ (Fig. 4). In skeletal muscle, the protein content of Glut4 was found to be significantly decreased in SL rats compared to NL, but no significant differences were observed in the protein levels of Irs-1 and Akt2 between the two groups (Fig. 5).

In order to evaluate whether the changes in protein content are associated with changes in the levels of 


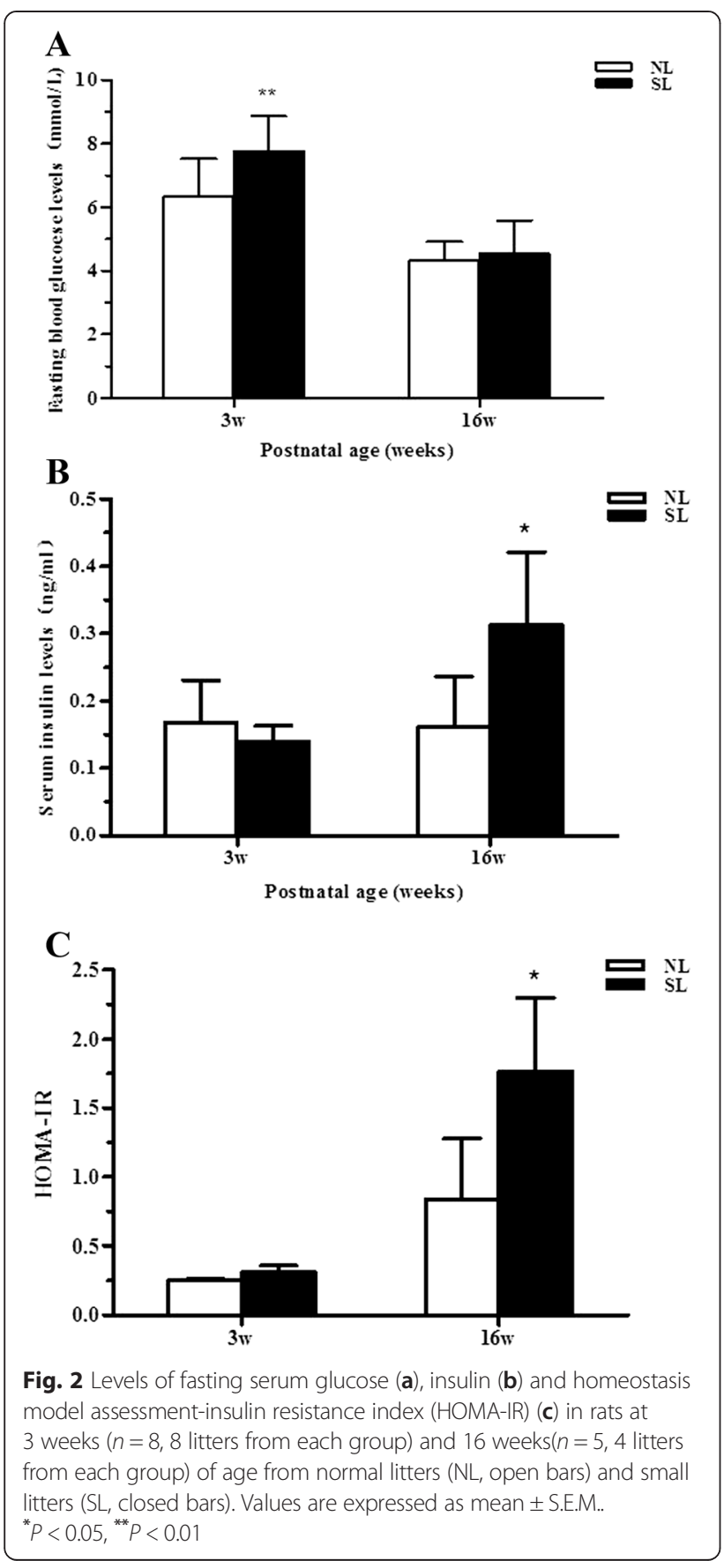

mRNA, quantitative real-time PCR was performed on mRNA isolated from adult SL and NL rats. At 16 weeks of age, early postnatal overnutrition resulted in a significant decrease in mRNA levels of Irs-1 and Glut4 $(P<0.05)$ in epididymal fat, paralleling the results of protein measurement (Fig. 6). In muscle a significant decrease in Glut4 mRNA $(P<0.05)$ was observed (Fig. 7$)$, consistent with the western blot data, in addition to a marked reduction in $A k t 2$ mRNA expression $(P<0.05$, Fig. 7$)$ which did not reflect a significant change at the protein level. In contrast,
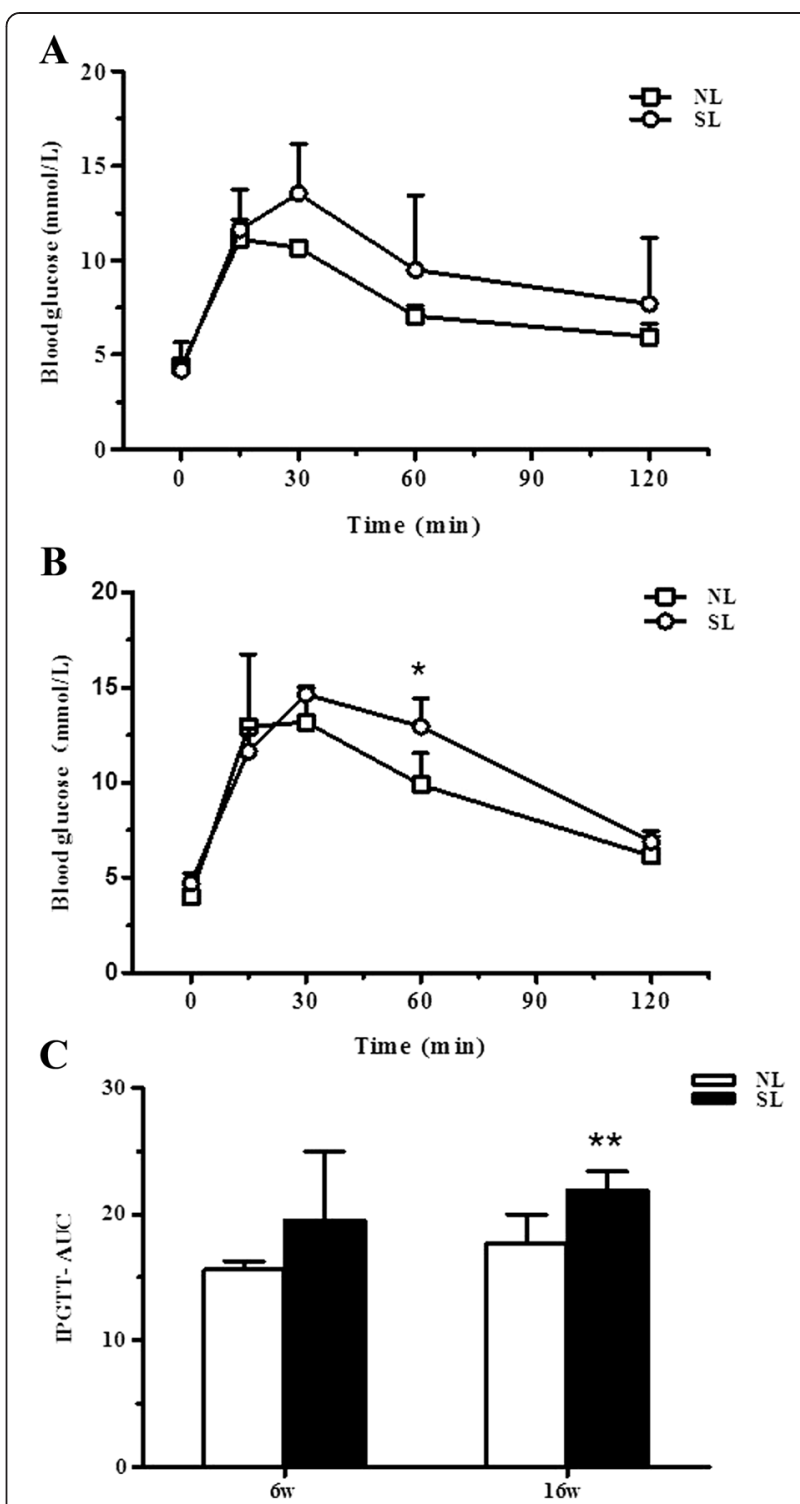

Fig. 3 Glucose tolerance in rats aged 6 and 14 weeks. Intraperitoneal glucose tolerance test (IPGTT) at 6 weeks (a) and 14 weeks (b) in rats from normal litters (NL, $\square$ ) and small litters $(\mathrm{SL}, \mathrm{o})$. Comparison of the area under the curve (AUC) (c) between NL (open bar) and SL (closed bar) rats at each time point. Results are expressed as mean \pm S.E.M.

( $n=5,4$ litters from each group). ${ }^{*} P<0.05,{ }^{* *} P<0.01$

the protein level of Akt2 in epididymal fat was significantly lower in SL rats compared to NL rats, unlike the mRNA expression levels $(P>0.05)$ (Fig. 6). In line with the protein comparison, there is no significant difference in Irs-1 mRNA expression between two groups in skeletal muscle (Fig. 7).

\section{Effect of early postnatal overnutrition on serum fatty acid metabolomics}

Numerous studies have shown that obesity induces an increase in circulating free fatty acids (FFAs), and this is 

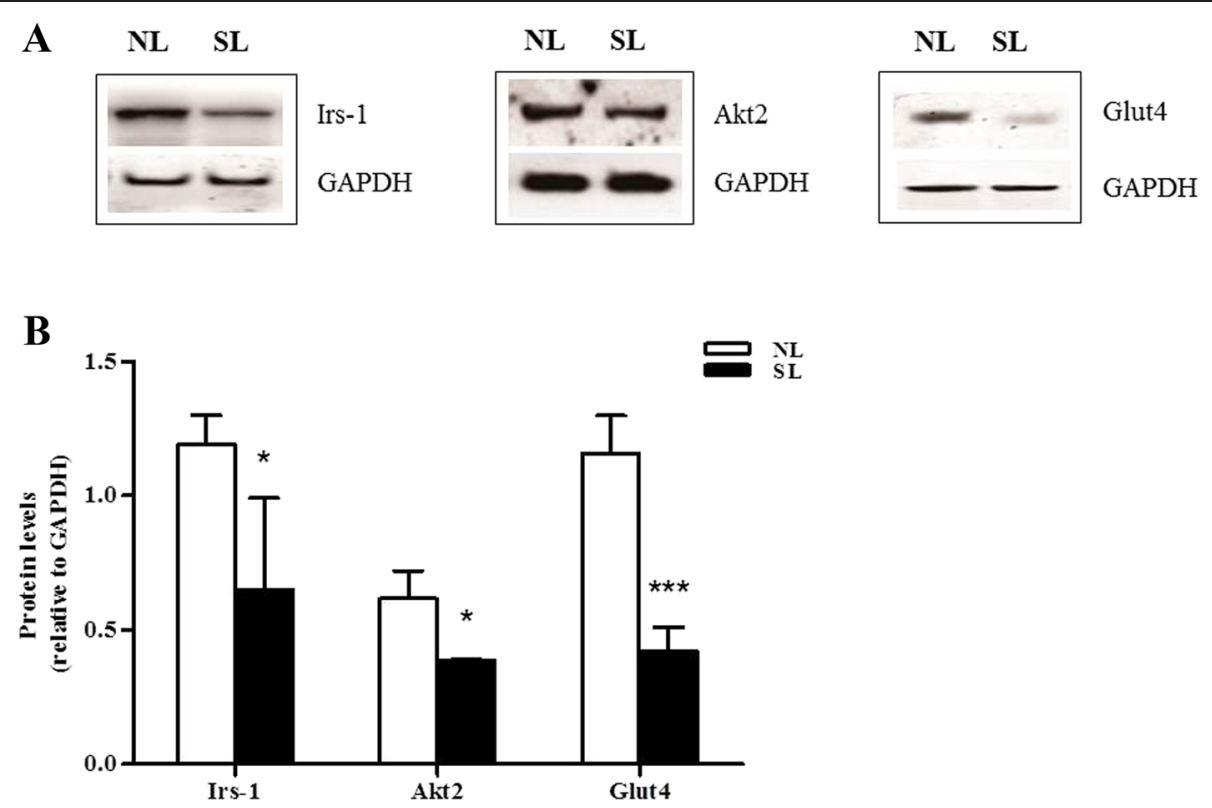

Fig. 4 Protein expression of key insulin signaling components in epididymal fat at 16 weeks. Protein levels of insulin receptor substrate-1 (Irs-1), protein kinase B (Akt2) and glucose transporter 4 (Glut4) in the epididymal fat of rats from normal litters (NL) and small litters (SL) were assessed by western blotting. Representative blots are shown in (a). Relative protein levels were quantified by scanning densitometry of the bands (b). Results are expressed as mean \pm S.E.M $\left(n=6,4\right.$ litters from each group). ${ }^{* *} P<0.01,{ }^{* * *} P<0.001$

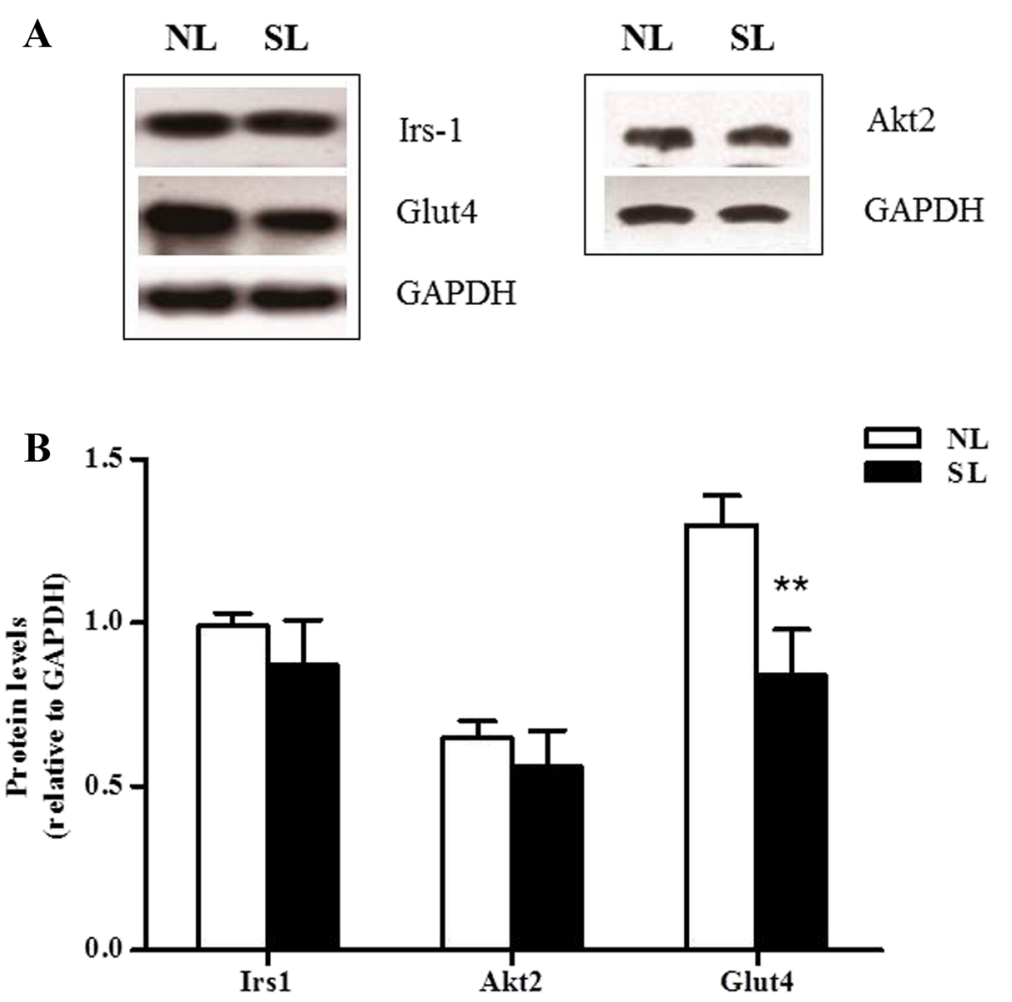

Fig. 5 Protein expression of key insulin signaling components in the gastrocnemius muscle at 16 weeks. Protein levels of Irs-1, Akt2 and Glut4 in the gastrocnemius of rats from NL and SL were assessed by western blotting. Representative blots are shown in (a). Relative protein levels were quantified by scanning densitometry of the bands (b). Results are expressed as mean \pm S.E.M $\left(n=6,4\right.$ litters from each group). ${ }^{* *} P<0.01$ 


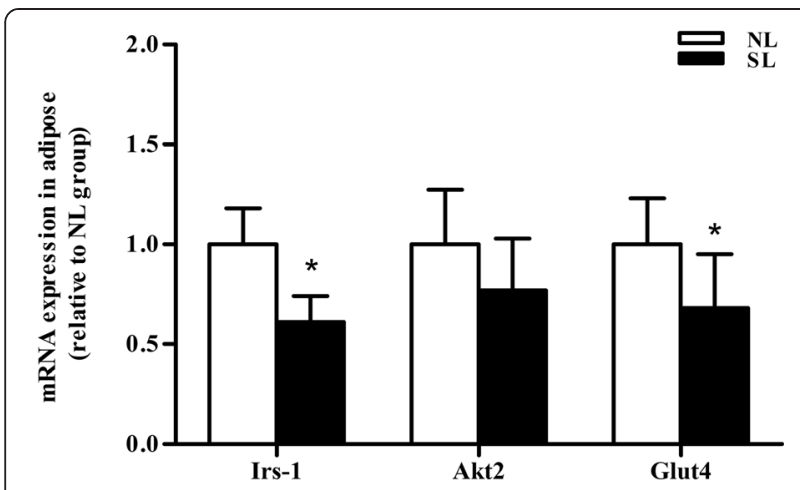

Fig. 6 mRNA expression of key insulin signaling components in epididymal fat at 16 weeks. mRNA level of Irs-1, Akt2 and Glut4 were assessed by quantitative PCR in the epididymal fat of rats from normal litter (NL, open bar) and small litter (SL, closed bar). Results are expressed as mean \pm S.E.M ( $n=6,4$ litters from each group). ${ }^{*} P<0.05$

considered to play an important role in the development of IR [18-21]. We therefore employed a metabolomics approach to investigate serum fatty acids profiles in rats at weaning (day 21) and at 16 weeks of age. Using gas chromatography-mass spectrometry (GC-MS), 11 fatty acids were detected in serum at weaning and 10 fatty acids were detected at 16 weeks of age. These fatty acids included saturated fatty acids (SFAs) (C12:0, C14:0, C15:0, C16:0 and C18:0), monounsaturated fatty acids (MUFAs) (C16:1 and C18:1), and polyunsaturated fatty acids (PUFAs) (C18:2n-6, C18:3n-3, C20:4n-6 and C20:5n-3). Lauric acid (C12:0) was identified in the serum of rats at weaning but not at 16 weeks. All the fatty acids identified except lauric acid (C12:0) are long chain fatty acids. Palmitic acid (C16:0), stearic acid (C18:0), oleic acid (C18:1), linoleic acid (C18:2n-6) and

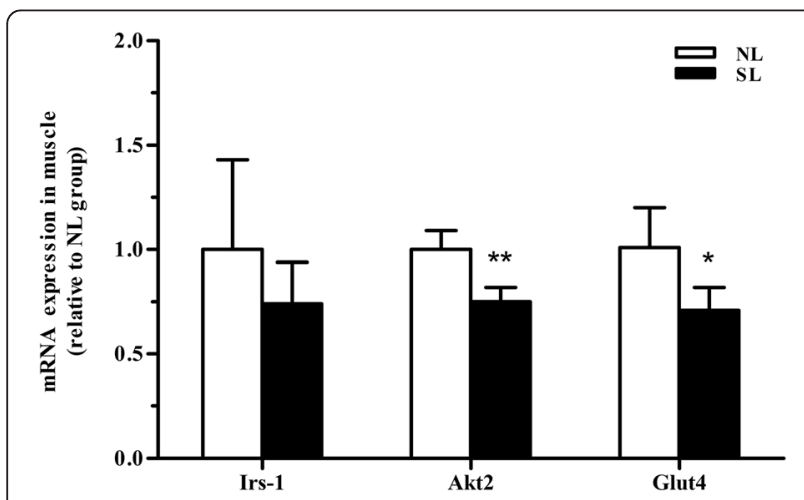

Fig. 7 mRNA expression of key insulin signaling components in the gastrocnemius muscle at 16 weeks. mRNA levels of Irs-1, Akt2 and Glut4 were assessed by quantitative PCR in the gastrocnemius of rats from normal litters (NL, open bars) and small litters (SL, closed bars). Results are expressed as mean \pm S.E.M $(n=6,4$ litters from each group). ${ }^{*} P<0.05,{ }^{* *} P<0.01$ arachidonic acid (C20:4n-6) accounted for the majority of all fatty acids (Table 3).

At 3 weeks of age, a significant increase $(P<0.05)$ was observed in the serum concentration of all fatty acids except for $\mathrm{C} 18: 3 \mathrm{n} 3$ in SL rats compared to $\mathrm{NL}$ rats (Table 3). This elevation in the overall level of serum fatty acids in the SL group may be attributed to the high fat content of milk and the increased calorie intake of these rats during early postnatal life. At 16 weeks, serum levels of several of the identified fatty acids were no longer significantly different between the two groups; however, significant increases in serum levels of C16:0, C16:1, C18:1 and C20:4n-6 (and the consequent elevation in total SFA and MUFA levels) in SL rats compared to NL persisted into adulthood $(P<0.05)$ (Table 3$)$. To determine the relationship between serum fatty acid levels and insulin resistance (estimated by the HOMAIR index) in adulthood, Pearson's correlation coefficients were calculated for each individual fatty acid at 16 weeks. This analysis revealed significantly positive correlations for myristic acid (C14:0), palmitic acid (C16:0), palmitoleic acid (C16:1) and oleic acid (C18:1) (Table 4).

\section{Discussion}

Overnutrition in early postnatal life, a critical window for development, can give rise to long-term consequences for body weight and metabolic diseases. Breast fed infants, compared to those given formula feeds, have lower daily calorie intakes and a $40 \%$ decreased risk of developing type 2 diabetes [22, 23]. Some studies have shown that formula feeding is a risk factor for later overweight [24, 25]. Quantitative and qualitative overnutrition associated with formula feeding during infancy has potential risks for later metabolic health [26]. In rats, early postnatal overnutrition caused by manipulations to produce small litters has been shown to cause persistent overweight, hyperinsulinemia, hyperleptinemia and IR $[8,27,28]$. SL pups have also been subjected to quantitative and qualitative overnutrition during early postnatal life [26, 29]. This overweight/obsese phenotype has been extensively investigated in terms of hypothalamic mechanisms; however, molecular mechanisms underlying the increased susceptibility to IR in peripheral organs are poorly appreciated. To the best of our knowledge, no study has yet investigated the effect of early postnatal overnutrition on serum fatty acid metabolomics. In this study, we focused on the consequences of overnutrition during early postnatal life on serum fatty acid profiles and alterations of insulin signaling cascades in skeletal muscle and visceral white adipose tissue in order to determine whether early nutritional experience may influence the levels of key components of the insulin signaling pathway which play an important role in IR. 
Table 3 Serum fatty acid profiles in 3 and 16 weeks old rats

\begin{tabular}{|c|c|c|c|c|}
\hline & $3 w k$ & & $16 w k$ & \\
\hline & $\mathrm{NL}(n=5)$ & $\mathrm{SL}(n=5)$ & $\mathrm{NL}(n=6)$ & $\operatorname{SL}(n=6)$ \\
\hline C12:0 & $3.19 \pm 1.03$ & $16.92 \pm 9.74^{*}$ & - & - \\
\hline C14:0 & $15.33 \pm 5.09$ & $34.8 \pm 12.09^{*}$ & $1.86 \pm 0.56$ & $2.51 \pm 0.55$ \\
\hline C15:0 & $2.15 \pm 0.25$ & $3.1 \pm 0.27^{*}$ & $1.92 \pm 0.73$ & $1.9 \pm 0.91$ \\
\hline C16:0 & $205.66 \pm 32.11$ & $313.67 \pm 70.04^{*}$ & $174.19 \pm 46.54$ & $241.28 \pm 24.38^{*}$ \\
\hline C16:1 & $2.91 \pm 0.64$ & $8.64 \pm 1.34^{* * *}$ & $5.86 \pm 2.13$ & $9.55 \pm 3.14^{*}$ \\
\hline C18:0 & $85.94 \pm 13.6$ & $138.86 \pm 31.22^{* * *}$ & $93.08 \pm 21.44$ & $122.06 \pm 23.42$ \\
\hline C18:1 & $78.06 \pm 15.52$ & $113.24 \pm 16.56^{*}$ & $56.27 \pm 18.42$ & $88.71 \pm 14.69^{*}$ \\
\hline C18:2n6 & $114.39 \pm 29.43$ & $173.90 \pm 40.52^{*}$ & $110.02 \pm 40.26$ & $145.95 \pm 13.11$ \\
\hline C18:3n3 & $2.74 \pm 1.69$ & $3.44 \pm 0.75$ & $1.73 \pm 1.05$ & $2.32 \pm 1.19$ \\
\hline$C 20: 4 n 6$ & $154.57 \pm 26.42$ & $291.87 \pm 72.56^{* *}$ & $176.61 \pm 56.01$ & $245.59 \pm 53.87^{*}$ \\
\hline$C 20: 5 n 3$ & $7.86 \pm 2.35$ & $14.92 \pm 1.83^{* *}$ & $5.07 \pm 1.68$ & $5.68 \pm 2.28$ \\
\hline SFAs & $312.26 \pm 50.3$ & $507.34 \pm 122.25^{* *}$ & $271.04 \pm 67.86$ & $367.86 \pm 46.39^{*}$ \\
\hline MUFAs & $80.97 \pm 15.56$ & $121.87 \pm 17.71^{* *}$ & $62.12 \pm 19.76$ & $98.25 \pm 14.62^{* *}$ \\
\hline n-6PUFAs & $268.96 \pm 52.33$ & $465.77 \pm 109.44^{* *}$ & $286.63 \pm 94.05$ & $391.54 \pm 60.78$ \\
\hline$n-3 P U F A s$ & $10.05 \pm 4.17$ & $18.37 \pm 1.17^{*}$ & $6.45 \pm 1.92$ & $8 \pm 3.16$ \\
\hline
\end{tabular}

Values are mean concentration $(\mu \mathrm{g} / \mathrm{ml}) \pm$ SEM ( $3 \mathrm{w}, \mathrm{n}=5,8$ litters from each group; $16 \mathrm{w}, \mathrm{n}=6,4$ litters from each group). NL: normal litter; SL: small litter; SFA: saturated fatty acid; MUFA: monounsaturated fatty acid; PUFA: polyunsaturated fatty acid. ${ }^{*} P<0.05,{ }^{* *} P<0.01,{ }^{* * * *} P<0.001$

Consistent with previous studies [27, 28, 30, 31], our data show that early overnutrition leads to a persistent increase in body weight and adipose tissue accumulation, adult-onset hyperinsulinemia, and IR. During the glucose tolerance tests, SL rats exhibited higher glycaemia and AUC at 14 weeks than NL rats, suggesting decreased insulin sensitivity in this group. We found no difference between the groups in the serum leptin concentration at 16 weeks of age. This is consistent with previous findings [31-34]. Leptin is mainly produced by subcutaneous adipocytes [35]. Adult SL rats are reported to have a normal subcutaneous fat mass, but a higher visceral fat mass [33]. However, visceral adipocytes have a lower leptin content than subcutaneous adipocytes due to adipocyte dysfunction [31]. This observation may explain the unchanged serum leptin concentration, and resulting unchanged food intake at 16 weeks of age. $\mathrm{Nu}$ merous mechanisms have been proposed to underlie IR in animals raised in small litters, including blunting of insulin signaling, increased levels of circulating fatty acid and some adipocytokines, increased oxidative stress, abnormal integration and projection of orexigenic and anorexigenic neurons, impairment of the hypothalamicpituitary-adrenal glucocorticoid axis, and aberrant epigenetic modifications [8, 27, 36-39].

Previous studies have shown that early postnatal overfeeding increases serum levels of free fatty acids (FFA) $[28,40]$, a finding that we confirmed in our model. FFA released from adipose tissue into the circulation have been shown to attenuate glucose transport by impairing insulin signaling in skeletal muscle and adipose tissue, resulting in decreased glycogenesis in these tissues and increased serum glucose [20, 41]. In addition, high FFA levels contribute to increased glucose output in liver and aggravate hyperglycemia, eventually leading to IR. IR in turn results in inhibition of lipolysis [42], further increasing circulating FFA levels and causing a vicious cycle which can lead to type 2 diabetes mellitus.

The insulin receptor signaling pathway is the major mechanism by which insulin target tissues maintain their systemic and local insulin sensitivity. Decreased expression of Irs-1, Akt2 and Glut4, all key components of the insulin signaling pathway, results in reduced insulin action and IR. Our data showed that Irs-1, Akt2 and Glut4

Table 4 Correlation between serum fatty acid concentrations and insulin resistance index (HOMA-IR) at 16 weeks

\begin{tabular}{llc}
\hline Fatty acid & $R$ & $P$-value \\
\hline C14:0 & $0.798^{* *}$ & 0.003 \\
C15:0 & 0.178 & 0.601 \\
C16:0 & $0.614^{*}$ & 0.044 \\
C16:1 & $0.745^{* *}$ & 0.008 \\
C18:0 & 0.382 & 0.247 \\
C18:1 & $0.674^{*}$ & 0.023 \\
C18:2n6 & 0.445 & 0.170 \\
C18:3n3 & 0.261 & 0.467 \\
C20:4n6 & 0.264 & 0.433 \\
C20:5n3 & 0.291 & 0.385 \\
\hline
\end{tabular}

$R$ indicates Pearson's correlation co-efficient calculated between serum fatty acid levels and the homeostatic model assessment-insulin resistance (HOMA-IR) index in NL and SL groups at 16 weeks of age. ${ }^{*} P<0.05,{ }^{* *} P<0.01$ 
levels dramatically decreased in epididymal fat of SL rats compared with NL rats, indicating that insulin signaling was severely impaired in visceral adipose tissue following overnutrition during early postnatal life. In gastrocnemius, mRNA levels of $A k t 2$ and Glut4 and protein levels of Glut4 also decreased, suggesting the insulin signaling was also blunted in skeletal muscle. These data confirm and extend previous findings using the same small litter size model [43, 44]. Low cellular Irs-1 expression was previously demonstrated to be associated with low Glut4 expression and impaired insulin-stimulated glucose transport in IR [45]. It is clear that IRS-1 gene disruption in mice leads to a marked resistance to the glucose-lowering effects of insulin [46]. Likewise, Akt2 deficiency in mice is associated with IR and a diabetes mellitus-like syndrome [47]. Abel et al. reported that mice which exhibit an adipose-selective reduction of Glut4 developed IR in muscle and liver, despite having no impairment of Glut4 expression in these tissues [48]. Thus, adipose tissue may contribute more to global glucose homeostasis than is reflected by its glucose uptake, which accounts for only 5$10 \%$ of the total glucose load $[45,49]$. For rats raised in small litters, the combination of low expression of Glut4 in both adipose tissue and skeletal muscle will inevitably exacerbate adult-onset IR. Surprisingly, in the present study, we did not observe a correlation between Akt2 mRNA and protein levels. Various regulatory mechanisms at the level of transcription, post-transcription, translation or protein degradation may contribute to this variation of mRNA and protein concentrations [50].

Not only the levels, but also the composition of circulating fatty acids may have an impact on the development of IR. To investigate this, we employed metabolomic profiling to identify and measure the levels of individual fatty acids in serum at 3 weeks and 16 weeks of age. We observed a sustained increase in the levels of SFA palmitic acid (C16:0), MUFAs palmitoleic acid (C16:1) oleic acid (C18:1), and PUFA arachidonic acid (C20:4n-6) in adult SL rats. SFAs are thought to contribute to IR by several mechanisms, including the activation of c-Jun N-terminal kinase (JNK)/IKB kinase (IкK) signaling [21], inhibition of AKT or IRS phosphorylation by their metabolites [51, 52], and the direct inhibition of GLUT4 activation in insulin target organs [53]. The attenuated action of insulin on circulating glucose levels causes the pancreas to secrete more insulin to maintain blood glucose homeostasis, leading to hyperglycemia and IR. Palmitic acid, which comprises the overwhelming majority of long chain SFAs, has been widely used as an inducer of IR in hepatocytes [54], adipocytes [55] and skeletal muscle cells [56]. We detected a significantly positive correlation between IR index and serum myristic and palmitic acid concentrations which is supported by a study by $\mathrm{Xu}$ et al., who reported that significantly raised myristic, palmitic and stearic acid levels in serum are associated with type 2 diabetes and increased fasting glucose levels using mass spectrometry-based metabolic profiling [57]. Palmitate not only directly interacts with the insulin receptor and IRS proteins via activation of protein kinase $C \theta[58,59]$, but also causes increased mitochondrial reactive oxygen species production, which is related to inhibition of insulin signaling in skeletal muscle cells [60]. Elevated palmitic acid in serum has furthermore been proposed as a diagnostic biomarker for IR [17, 61].

In this work, two MUFAs, palmitoleic acid (C16:1) and oleic acid (C18:1), were persistently and significantly elevated in the serum of SL rats. Both these fatty acids also positively correlated with IR index in adult rats, consistent with the fact that both have been previously suggested as diagnostic biomarkers for IR [17, 61]. An increased concentration of palmitoleate has been reported to be associated with both raised triglycerides levels and with IR [14]. A study by Kusunokiy and colleagues showed that the serum concentrations of palmitoleic acid and oleic acid were positively correlated with HOMA-IR in individuals with type 2 diabetes mellitus [15]. Oleic acid was shown to downregulate GLUT4 expression in skeletal muscle cells via NF-kB and sterol-regulatory-elementbinding-protein-1 (SREBP1), which may participate in the fatty acid related pathophysiology of IR [62].

Compared with long chain SFAs and MUFAs, the exact effect of long chain PUFAs on IR are unknown. We detected two n-6 PUFAs in serum, linoleic acid $(\mathrm{C} 18: 2 \mathrm{n}-6)$ and arachidonic acid (AA, C20:4n-6), of which the latter was consistently elevated in SL rats compared with NL rats. Previous studies of the effect of AA on IR have been contradictory. Supplementation of AA was reported to prevent whole-body IR induced by a high-fat diet in rats, suggesting a protective effect [63]. However, as a precursor to inflammatory transmitters such as prostaglandins and leukotrienes, AA may aggravate IR via the inflammatory pathway. Moreover, Williams and colleagues identified a positive relationship between AA content in adipose tissue and metabolism dysregulation including abdominal obesity, hypertriglyceridemia and elevated fasting glucose in adult participants [64]. However, we found no evidence of a positive correlation between AA and HOMA-IR. The precise effect of increased serum concentration of AA in SL rats in the current work is unclear and further studies will be needed to confirm and complete our knowledge in this field, such as systemic and local evaluation of IR and inflammation after AA supplementation.

\section{Conclusions}

Our data provide evidence that early postnatal overnutrition induced by small litters can lead to sustained increased body weight in the offspring, the accumulation of white visceral adipose tissue, elevated serum fatty acid 
and triglyceride levels, and increased fasting serum glucose in adult male rats. Decreased levels of the main components of the insulin receptor signaling pathway, Irs-1, Akt2 and Glut4, in white visceral adipose tissue and skeletal muscle may be responsible for adult-onset IR in SL rats. Ours is the first study to report that persistent high serum levels of SFA palmitic acid (C16:0), MUFAs palmitoleic acid (C16:1) and oleic acid (C18:1), due to nutrition overload during early postnatal life, may play a role in the development of IR in adulthood by interfering with the insulin receptor signaling pathway. However, it should be noted that the power of the current study to identify specific fatty acids as biomarkers for IR is limited by the fact that serum fatty acid profiles were only assessed at 3 and 16 weeks. In the future, a longitudinal study will be needed to provide more definitive evidence for the correlation between changes of fatty acid profile and adult-onset IR. Our findings strengthen the evidence for the potency and long-term effects of early postnatal overnutrion in reprogramming metabolic regulatory mechanisms. Avoiding overfeeding during early postnatal life appears to be an important and effective means of preventing adverse postnatal programming, and long term metabolic problems.

\section{Methods}

\section{Animals and experimental design}

This study was approved by the University Committee on the Use and Care of Animals at Shanghai University. Sprague-Dawley rats (Slaccas, Shanghai, China) were housed under controlled temperature conditions $(23 \pm$ $2{ }^{\circ} \mathrm{C}$ ) and a $12 \mathrm{~h} \mathrm{light/dark}$ cycle with ad libitum access to a standard rodent laboratory chow $(14.44 \mathrm{~kJ} / \mathrm{g})$ and water. The mean size of birth litters used in the study was 10-12 pups/dam. At postnatal day 2, litters were assigned randomly to either NL or SL groups. For the SL group, litter size was adjusted to three male pups/ dam. NL pups were raised in litters of 10 pups/dam, containing male and female pups. All the pups were nursed by their natural dams. The pups were weaned on postnatal day 21 , and three male pups from each litter were seperated. After that, all male rats were housed three per cage and fed standard chow and water ad libitum. Only male rats were analyzed in the study.

\section{Serum and tissue collection}

At 3 and 16 weeks, rats were anesthetized by an intraperitoneal injection of chloral hydrate $(300 \mathrm{mg} / \mathrm{kg}$ body weight) after overnight fasting (12 h) and blood was obtained from the heart. The blood was collected in nonheparinized tubes and centrifuged $\left(3100 \mathrm{~g}, 25{ }^{\circ} \mathrm{C}\right.$, $15 \mathrm{~min})$. The separated serum was stored at $-80{ }^{\circ} \mathrm{C}$. Gastrocnemius, epididymal and perirenal fat pads were dissected, weighed and frozen in liquid nitrogen and stored at $-80{ }^{\circ} \mathrm{C}$.

\section{Body weight}

Body weights of rats raised in SL and NL were monitored on a weekly basis. Weighing was performed between the hours of 8 am and $9 \mathrm{am}$.

\section{Biochemical analysis}

Serum glucose content was determined using a glucose oxidase assay (Rongsheng, Shanghai, China). Levels of triglycerides, high-density lipoprotein cholesterol (HDL-C) and free fatty acids (FFA) were measured using a HITACHI 7180 analyzer with enzymatic reagents (Wako, Osaka, Japan). Serum insulin and leptin content were determined using radioimmunoassay kits (Millipore, Billerica, MA, USA) according to the manufacturer's instructions. The homeostatic model assessment-insulin resistance (HOMAIR) index was calculated as follows:

$$
\begin{aligned}
\mathrm{HOMA}-\mathrm{IR}= & {[\text { fasting serum glucose }(\mathrm{mmol} / \mathrm{L})] } \\
& \times[\text { fasting serum insulin }(\mathrm{mU} / \mathrm{L})] / 22.5
\end{aligned}
$$

\section{Intraperitoneal glucose tolerance test measurement}

The intraperitoneal glucose tolerance test (IPGTT) was performed on rats aged 6 weeks and 14 weeks. Rats were fasted overnight for $12 \mathrm{~h}$ and a fasting blood sample was taken from a tail vein, then the rats were injected intraperitoneally with $2.0 \mathrm{~g}$ D-glucose $/ \mathrm{kg}$ body weight. Thereafter, blood samples were drawn at 15, 30, 60 and 120 min timepoints and glucose levels were measured using a blood glucose monitoring system (One Touch Sure Step, Johnson \& Johnson, New Jersey, USA). The area under the curve (AUC) of IPGTT was calculated using the following formula:

$$
\begin{aligned}
\mathrm{AUC}= & 0.125 \times \mathrm{BG} 0+0.25 \times \mathrm{BG} 15+0.375 \\
& \times \mathrm{BG} 30+0.75 \times \mathrm{BG} 60+0.5 \\
& \times \mathrm{BG} 120
\end{aligned}
$$

(BGx: the blood glucose level at 0, 15, 30, 60 and $120 \mathrm{~min})$

\section{Quantitative real-time polymerase chain reaction (PCR)}

Quantitative real-time PCR was carried out as previous reported [65]. Total RNA was isolated from epididymal fat and gastrocnemius muscles using TRIzol reagent (Invitrogen, USA) according to the kit protocol. The fragmented RNA was reverse-tanscribed into cDNA with the SuperScript double-stranded cDNA synthesis kit (Invitrogen, USA). Primers for amplification of insulin receptor substrate 1 (Irs-1), protein kinase B (Akt2), glucose transporter 4 (Glut4) and the loading control GAPDH were designed using Primer Express Software 
5.0 (ABI, USA) (Table 5). Real-time PCR was performed on an ABI 7500 instrument (ABI, USA) with a total of $20 \mu \mathrm{L}$ reaction volumes containing $10 \mu \mathrm{L}$ of $2 \mathrm{X}$ SYBR Green Mix (Invitrogen, USA), $1 \mu \mathrm{L}$ of cDNA and $0.8 \mu \mathrm{L}$ of paired specific primers. The reactions were incubated at $50{ }^{\circ} \mathrm{C}$ for $2 \mathrm{~min}$ and $95{ }^{\circ} \mathrm{C}$ for $5 \mathrm{~min}$, followed by 39 cycles of amplification $\left(95^{\circ} \mathrm{C}\right.$ for $15 \mathrm{~s}, 60^{\circ} \mathrm{C}$ for $\left.31 \mathrm{~s}\right)$. They were then ramped from $60{ }^{\circ} \mathrm{C}$ to $95{ }^{\circ} \mathrm{C}$ to obtain the melting curve. Relative mRNA levels were calculated according to the comparative $2^{-\Delta \Delta \mathrm{Ct}}$ method [66] and expressed as the fold change compared to the age-matched NL group.

\section{Protein preparation and western blotting}

Frozen tissue samples were weighed and homogenized in lysis buffer with protease inhibitor cocktail on ice using a Retsch MM301 mixer mill (Retsch GmbH, Germany). After centrifugation (13000 g) at $4{ }^{\circ} \mathrm{C}$ for $1 \mathrm{~h}$, supernatants were transferred to fresh tubes. Protein concentrations in the final supernatants were determined using the bicinchoninic acid (BCA) method (Beyotime Biotechnology, China). For each sample, $50 \mu \mathrm{g}$ protein was diluted in 2X SDS-PAGE loading buffer and loaded on a $10 \%$ polyacrylamide gel. Proteins were transferred from the gel to a $0.22 \mu \mathrm{M}$ PVDF membrane using a membrane transfer apparatus (Wealtec, USA). PVDF membranes containing proteins were then rinsed with $1 \mathrm{X}$ TBST buffer and blocked in $5 \%$ non-fat milk liquid for $2 \mathrm{~h}$. The blocked membrane was placed in a hybridization bag, and primary antibodies anti-IRS1 (Cell Signaling Technology, USA), anti-AKT2 (Cell Signaling Technology, USA), anti-GLUT4 (Santa Cruz Biotechnology, USA) and anti-GAPDH (Solarbio, China) were added in $5 \%$ milk at 1:500, 1:500, 1:200 and 1:500 dilutions, respectively. Membranes were then rinsed and incubated in goat anti-rabbitHRP secondary antibody (Beyotime Biotechnology, China), diluted 1:10000 in $5 \%$ milk. The signal was detected by SuperSignal West Pico Chemiluminescent Substrate (Thermo scientific, USA). The results were analyzed using Image J software and normalized to GAPDH.

Table 5 Primers for gene expression analysis

\begin{tabular}{ll}
\hline Genes & Forward primer $\left(5^{\prime} \rightarrow 3^{\prime}\right)$ \\
& Reversed primer $\left(5^{\prime} \rightarrow 3^{\prime}\right)$ \\
Irs-1 & GTGCCAAGCAACAAGAAAGC \\
& TCAGAGCAGAGGACCGTAT \\
Akt2 & CCACGACCCAACACCTT \\
& CCTTGCTGACCGCTACCT \\
Glut4 (SIc2a4) & GGCTGTGAGTGGTGCTT \\
& GGTTTCTGCTCCCTATCGT \\
Gapdh & GGCACAGTCAAGGCTGAGAATG \\
& ATGGTGGTGAAGACGCAGTA \\
\hline
\end{tabular}

\section{Serum fatty acid metabolomics}

Acid-catalyzed methyl esterification was used to obtain organic phase samples for fatty acid content of serum sample. $\mathrm{BF}_{3}$-methanol $(14 \%, 1 \mathrm{ml})$ and internal lipid standard $\mathrm{C} 19: 0(1 \mathrm{mg} / \mathrm{ml}, 10 \mu \mathrm{l})$ were added to every $50 \mu \mathrm{l}$ serum sample and incubated at $80{ }^{\circ} \mathrm{C}$ for $10 \mathrm{~min}$. Water $(1 \mathrm{ml})$ and hexane $(1 \mathrm{ml})$ were added and the samples were vortex mixed for $1 \mathrm{~min}$, then centrifuged at $6000 \mathrm{~g}$ for $1 \mathrm{~min}$. The upper (organic) layer was collected for GC-MS analysis.

All GC-MS analyses were performed using a 7000B Triple Quadrupole GC-MS System (Agilent, CA, USA). The organic samples were injected with a split ratio of 10:1 onto a $30 \mathrm{~m} \times 0.25 \mathrm{~mm}$ VF-WAXms column (Agilent, CA, USA). The injector temperature was $250{ }^{\circ} \mathrm{C}$ and the helium carrier gas was used at a flow rate of $1 \mathrm{ml} / \mathrm{min}$. The column temperature was held at $180{ }^{\circ} \mathrm{C}$ for $1 \mathrm{~min}$, then increased by $3{ }^{\circ} \mathrm{C} / \mathrm{min}$ to $240{ }^{\circ} \mathrm{C}$ and held at $240{ }^{\circ} \mathrm{C}$ for $10 \mathrm{~min}$ [ion source $=280{ }^{\circ} \mathrm{C}$; electron ionization $(\mathrm{EI})=70 \mathrm{eV}]$.

Each individual peak was integrated and normalized (Agilent Mass Hunter Software, Aglient, CA, USA). Overlapping peaks were separated using traces of single ions. Peak assignment was based on mass fragmentation patterns matched to the National Institute of Standards and Technology library, and a fatty acid methyl ester (FAME) standard mix (Supelco 37 component FAME mix, Sigma-Aldrich, Shanghai, China).

\section{Statistical analysis}

Results are expressed as mean \pm S.E.M. Body weights and IPGTTs were analyzed by two-way ANOVA with repeated measures followed by a post hoc least significance difference test (SPSS 17.0). Organ weights, serum biochemistry, serum fatty acid profile, serum leptin and insulin concentrations, HOMA-IR, mRNA value and western blot results were analyzed using Student's $t$-test. Correlation coefficients between HOMA-IR and individual serum fatty acids were calculated according to the Pearson correlation test. Significant differences were defined as $P<0.05$.

\section{Abbreviations}

IR: Insulin resistance; NL: Normal litter; SL: Small litter; IRS: Insulin receptor substrate; Akt2: Protein kinase B; GLUT4: Glucose transporter 4; FFA: Free fatty acid; IPGTT: Intraperitoneal glucose tolerance test; AUC: Area under the curve; HOMA-IR: Homeostatic model assessment-insulin resistance; HDL-C: High density lipoprotein-cholesterol; SFAs: Saturated fatty acids;

MUFAs: Monounsaturated fatty acids; PUFAs: Polyunsaturated fatty acids.

\section{Competing interests}

The authors declare that they have no competing interests.

\section{Authors' contribution}

FB conceived the study, carried out animal and molecular experiment and drafted the manuscript. SJH and JJ participated in molecular experiment and performed statistical analysis. LF and YZY participated in animal model. JYQ participated in serum fatty acid profile analysis. CW participated in study 
design and coordination and helped to draft the manuscript. All authors read and approved the final manuscript.

\section{Acknowledgements}

This work was supported by Shanghai Municipal Commission of Health and Family Planning Grants No.201440441

\begin{abstract}
Author details
${ }^{1}$ Xin Hua Hospital, Shanghai Jiao Tong University School of Medicine, 1665 Kongjiang Road, Shanghai 200092, China. ${ }^{2}$ Shanghai Key Laboratory of Pediatric Gastroenterology and Nutrition, 1665 Kongjiang Road, Shanghai 200092, China. ${ }^{3}$ Shanghai Institute for Pediatric Research, Shanghai Jiao Tong University School of Medicine, 1665 Kongjiang Road, Shanghai 200092, China. ${ }^{4}$ Shanghai Center for Bioformation Technology, 1278 Keyuan Road, Shanghai 201203, China. ${ }^{5}$ Shanghai University of Traditional Chinese Medicine, 1200 Cailun Road, Shanghai 201203, China. ${ }^{6}$ Department of Neonatology, Shanghai Children's Medical Center, Shanghai Jiao Tong University School of Medicine, 1678 Dongfang Road, Shanghai 200127, China. ${ }^{7}$ School of Public Health, Physiotherapy \& Sports Science, University College Dublin, Belfield, Dublin 4, Ireland.
\end{abstract}

Received: 20 April 2015 Accepted: 14 August 2015 Published online: 26 August 2015

\section{References}

1. Xu Y, Wang L, He J, Bi Y, Li M, Wang T, et al. Prevalence and control of diabetes in Chinese adults. JAMA. 2013;310:948-59.

2. Stern MP. Diabetes and cardiovascular disease. The "common soil" hypothesis. Diabetes. 1995;44:369-74.

3. Toschke AM, Grote V, Koletzko B, von Kries R. Identifying children at high risk for overweight at school entry by weight gain during the first 2 years. Arch Pediatr Adolesc Med. 2004;158:449-52.

4. Patel MS, Srinivasan M. Metabolic programming due to alterations in nutrition in the immediate postnatal period. J Nutr. 2010;140:658-61.

5. Taveras EM, Rifas-Shiman SL, Sherry B, Oken E, Haines J, Kleinman K, et al. Crossing growth percentiles in infancy and risk of obesity in childhood. Arch Pediatr Adolesc Med. 2011;165:993-8.

6. Plagemann A, Harder T, Rake A, Voits M, Fink H, Rohde W, et al. Perinatal elevation of hypothalamic insulin, acquired malformation of hypothalamic galaninergic neurons, and syndrome x-like alterations in adulthood of neonatally overfed rats. Brain Res. 1999:836:146-55.

7. Cunha AC, Pereira RO, Pereira MJ, Soares Vde M, Martins MR, Teixeira MT, et al. Long-term effects of overfeeding during lactation on insulin secretion-the role of GLUT-2. J Nutr Biochem. 2009;20:435-42.

8. Conceicao EP, Franco JG, Oliveira E, Resende AC, Amaral TA, Peixoto-Silva N, et al. Oxidative stress programming in a rat model of postnatal early overnutrition-role of insulin resistance. J Nutr Biochem. 2013;24:81-7.

9. Saltiel AR, Kahn CR. Insulin signalling and the regulation of glucose and lipid metabolism. Nature. 2001;414:799-806.

10. Rossetti L, Stenbit AE, Chen W, Hu M, Barzilai N, Katz EB, et al. Peripheral but not hepatic insulin resistance in mice with one disrupted allele of the glucose transporter type 4 (GLUT4) gene. J Clin Invest. 1997;100:1831-9.

11. Li J, Houseknecht KL, Stenbit AE, Katz EB, Charron MJ. Reduced glucose uptake precedes insulin signaling defects in adipocytes from heterozygous GLUT4 knockout mice. FASEB J. 2000;14:1117-25.

12. Huang S, Czech MP. The GLUT4 glucose transporter. Cell Metab. 2007;5:237-52.

13. Hodge AM, English DR, O'Dea K, Sinclair AJ, Makrides M, Gibson RA, et al. Plasma phospholipid and dietary fatty acids as predictors of type 2 diabetes: interpreting the role of linoleic acid. Am J Clin Nutr. 2007;86:189-97.

14. Mozaffarian D, Cao H, King IB, Lemaitre RN, Song X, Siscovick DS, et al. Circulating palmitoleic acid and risk of metabolic abnormalities and new-onset diabetes. Am J Clin Nutr. 2010;92:1350-8.

15. Kusunoki M, Tsutsumi K, Nakayama M, Kurokawa T, Nakamura T, Ogawa H, et al. Relationship between serum concentrations of saturated fatty acids and unsaturated fatty acids and the homeostasis model insulin resistance index in Japanese patients with type 2 diabetes mellitus. J Med Invest. 2007:54:243-7.

16. Friedrich N. Metabolomics in diabetes research. J Endocrinol. 2012;215:29-42.

17. Kotronen A, Velagapudi VR, Yetukuri L, Westerbacka J, Bergholm R, Ekroos K, et al. Serum saturated fatty acids containing triacylglycerols are better markers of insulin resistance than total serum triacylglycerol concentrations. Diabetologia. 2009:52:684-90.

18. Eckel RH, Grundy SM, Zimmet PZ. The metabolic syndrome. Lancet. 2005;365:1415-28

19. Griffin ME, Marcucci MJ, Cline GW, Bell K, Barucci N, Lee D, et al. Free fatty acid-induced insulin resistance is associated with activation of protein kinase $C$ theta and alterations in the insulin signaling cascade. Diabetes. 1999:48:1270-4.

20. Krebs M, Roden M. Nutrient-induced insulin resistance in human skeletal muscle. Curr Med Chem. 2004;11:901-8.

21. Glass CK, Olefsky JM. Inflammation and lipid signaling in the etiology of insulin resistance. Cell Metab. 2012;15:635-45.

22. Owen CG, Martin RM, Whincup PH, Smith GD, Cook DG. Does breastfeeding influence risk of type 2 diabetes in later life? A quantitative analysis of published evidence. Am J Clin Nutr. 2006;84:1043-54.

23. Heinig MJ, Nommsen LA, Peerson JM, Lonnerdal B, Dewey KG. Energy and protein intakes of breast-fed and formula-fed infants during the first year of life and their association with growth velocity: the DARLING Study. Am J Clin Nutr. 1993;58:152-61.

24. Stettler N, Zemel BS, Kumanyika S, Stallings VA. Infant weight gain and childhood overweight status in a multicenter, cohort study. Pediatrics. 2002;109:194-9.

25. Ong KK, Ahmed ML, Emmett PM, Preece MA, Dunger DB. Association between postnatal catch-up growth and obesity in childhood: prospective cohort study. BMJ. 2000;320:967-71.

26. Plagemann A, Harder T, Schellong K, Schulz S, Stupin JH. Early postnatal life as a critical time window for determination of long-term metabolic health. Best Pract Res Clin Endocrinol Metab. 2012;26:641-53.

27. Liu HW, Mahmood S, Srinivasan M, Smiraglia DJ, Patel MS. Developmental programming in skeletal muscle in response to overnourishment in the immediate postnatal life in rats. J Nutr Biochem. 2013;24:1859-69.

28. Boullu-Ciocca S, Achard V, Tassistro V, Dutour A, Grino M. Postnatal programming of glucocorticoid metabolism in rats modulates high-fat diet-induced regulation of visceral adipose tissue glucocorticoid exposure and sensitivity and adiponectin and proinflammatory adipokines gene expression in adulthood. Diabetes. 2008;57:669-77.

29. Fiorotto ML, Burrin DG, Perez M, Reeds PJ. Intake and use of milk nutrients by rat pups suckled in small, medium, or large litters. Am J Physiol. 1991;260:R1104-13.

30. Hou M, Liu Y, Zhu L, Sun B, Guo M, Buren J, et al. Neonatal overfeeding induced by small litter rearing causes altered glucocorticoid metabolism in rats. PLOS ONE. 2011;6, e25726.

31. Conceicao EP, Trevenzoli IH, Oliveira E, Franco JG, Carlos AS, NascimentoSaba CC, et al. Higher white adipocyte area and lower leptin production in adult rats overfed during lactation. Horm Metab Res. 2011;43:513-6.

32. Glavas MM, Kirigiti MA, Xiao XQ, Enriori PJ, Fisher SK, Evans AE, et al. Early overnutrition results in early-onset arcuate leptin resistance and increased sensitivity to high-fat diet. Endocrinology. 2010;151:1598-610.

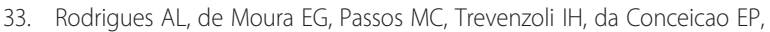
Bonono IT, et al. Postnatal early overfeeding induces hypothalamic higher SOCS3 expression and lower STAT3 activity in adult rats. J Nutr Biochem. 2011;22:109-17.

34. Rodrigues AL, de Moura EG, Passos MC, Dutra SC, Lisboa PC. Postnatal early overnutrition changes the leptin signalling pathway in the hypothalamic-pituitary-thyroid axis of young and adult rats. J Physiol. 2009;587:2647-61

35. Dusserre $E$, Moulin P, Vidal H. Differences in mRNA expression of the proteins secreted by the adipocytes in human subcutaneous and visceral adipose tissues. Biochim Biophys Acta. 2000;1500:88-96.

36. Habbout A, Li N, Rochette L, Vergely C. Postnatal Overfeeding in Rodents by Litter Size Reduction Induces Major Short- and Long-Term Pathophysiological Consequences. J Nutr. 2013;143:553-62.

37. Plagemann A, Roepke K, Harder T, Brunn M, Harder A, Wittrock-Staar M, et al. Epigenetic malprogramming of the insulin receptor promoter due to developmental overfeeding. J Perinat Med. 2010;38:393-400.

38. Boullu-Ciocca S, Dutour A, Guillaume V, Achard V, Oliver C, Grino M. Postnatal diet-induced obesity in rats upregulates systemic and adipose tissue glucocorticoid metabolism during development and in adulthood: its relationship with the metabolic syndrome. Diabetes. 2005;54:197-203.

39. Davidowa $H$, Plagemann A. Insulin resistance of hypothalamic arcuate neurons in neonatally overfed rats. Neuroreport. 2007;18:521-4. 
40. Kappeler L, De Magalhaes FC, Leneuve P, Xu J, Brunel N, Chatziantoniou C, et al. Early postnatal nutrition determines somatotropic function in mice. Endocrinology. 2009;150:314-23.

41. Shulman RG, Bloch $\mathrm{G}$, Rothman DL. In vivo regulation of muscle glycogen synthase and the control of glycogen synthesis. Proc Natl Acad Sci U S A. 1995;92:8535-42.

42. Rosen ED, Spiegelman BM. Adipocytes as regulators of energy balance and glucose homeostasis. Nature. 2006;444:847-53.

43. Rodrigues AL, De Souza EP, Da Silva SV, Rodrigues DS, Nascimento AB, Barja-Fidalgo $C$, et al. Low expression of insulin signaling molecules impairs glucose uptake in adipocytes after early overnutrition. J Endocrinol. 2007;195:485-94.

44. Liu Z, Lim CY, Su MY, Soh SL, Shui G, Wenk MR, et al. Neonatal overnutrition in mice exacerbates high-fat diet-induced metabolic perturbations. J Endocrinol. 2013;219:131-43.

45. Carvalho E, Jansson PA, Nagaev I, Wenthzel AM, Smith U. Insulin resistance with low cellular IRS-1 expression is also associated with low GLUT4 expression and impaired insulin-stimulated glucose transport. FASEB J. 2001;15:1101-3.

46. Tamemoto H, Kadowaki T, Tobe K, Yagi T, Sakura H, Hayakawa T, et al. Insulin resistance and growth retardation in mice lacking insulin receptor substrate-1. Nature. 1994;372:182-6.

47. Cho H, Mu J, Kim JK, Thorvaldsen JL, Chu Q, Crenshaw 3rd EB, et al. Insulin resistance and a diabetes mellitus-like syndrome in mice lacking the protein kinase Akt2 (PKB beta). Science. 2001;292:1728-31.

48. Abel ED, Peroni O, Kim JK, Kim YB, Boss O, Hadro E, et al. Adipose-selective targeting of the GLUT4 gene impairs insulin action in muscle and liver. Nature. 2001:409:729-33.

49. Marin $P$, Rebuffe-Scrive M, Smith U, Bjorntorp P. Glucose uptake in human adipose tissue. Metabolism. 1987;36:1154-60.

50. Vogel C, Marcotte EM. Insights into the regulation of protein abundance from proteomic and transcriptomic analyses. Nat Rev Genet. 2012;13:227-32.

51. Samuel VT, Shulman Gl. Mechanisms for insulin resistance: common threads and missing links. Cell. 2012;148:852-71.

52. Stratford S, Hoehn KL, Liu F, Summers SA. Regulation of insulin action by ceramide: dual mechanisms linking ceramide accumulation to the inhibition of Akt/protein kinase B. J Biol Chem. 2004;279:36608-15.

53. Van Epps-Fung M, Williford J, Wells $A$, Hardy RW. Fatty acid-induced insulin resistance in adipocytes. Endocrinology. 1997;138:4338-45.

54. Ishii M, Maeda A, Tani S, Akagawa M. Palmitate induces insulin resistance in human HepG2 hepatocytes by enhancing ubiquitination and proteasomal degradation of key insulin signaling molecules. Arch Biochem Biophys. 2015;566:26-35.

55. Chavez JA, Summers SA. Characterizing the effects of saturated fatty acids on insulin signaling and ceramide and diacylglycerol accumulation in 3 T3-L1 adipocytes and C2C12 myotubes. Arch Biochem Biophys. 2003;419:101-9.

56. Massao Hirabara S, de Oliveira Carvalho CR, Mendonca JR, Piltcher Haber E, Fernandes LC, Curi R. Palmitate acutely raises glycogen synthesis in rat soleus muscle by a mechanism that requires its metabolization (Randle cycle). FEBS Lett. 2003;541:109-14.

57. Xu F, Tavintharan S, Sum CF, Woon K, Lim SC, Ong CN. Metabolic signature shift in type 2 diabetes mellitus revealed by mass spectrometry-based metabolomics. J Clin Endocrinol Metab. 2013;98:E1060-5.

58. Benoit SC, Kemp CJ, Elias CF, Abplanalp W, Herman JP, Migrenne S, et al. Palmitic acid mediates hypothalamic insulin resistance by altering PKC-theta subcellular localization in rodents. J Clin Invest. 2009;119:2577-89.

59. Vogt MC, Bruning JC. CNS insulin signaling in the control of energy homeostasis and glucose metabolism - from embryo to old age. Trends Endocrinol Metab. 2013:24:76-84

60. Yuzefovych L, Wilson G, Rachek L. Different effects of oleate vs. palmitate on mitochondrial function, apoptosis, and insulin signaling in L6 skeletal muscle cells: role of oxidative stress. Am J Physiol Endocrinol Metab. 2010;299:E1096-105.

61. Roberts LD, Koulman A, Griffin JL. Towards metabolic biomarkers of insulin resistance and type 2 diabetes: progress from the metabolome. Lancet Diabetes Endocrinol. 2014;2:65-75.

62. Poletto AC, Furuya DT, David-Silva A, Ebersbach-Silva P, Lellis Santos C, Correa-Giannella ML, et al. Oleic and linoleic fatty acids downregulate Slc2a4/GLUT4 expression via NFKB and SREBP1 in skeletal muscle cells. Mol Cell Endocrinol. 2015:401:65-72.
63. Wu M, Wang X, Duan Q, Lu T. Arachidonic acid can significantly prevent early insulin resistance induced by a high-fat diet. Ann Nutr Metab. 2007:51:270-6.

64. Williams ES, Baylin A, Campos H. Adipose tissue arachidonic acid and the metabolic syndrome in Costa Rican adults. Clin Nutr. 2007;26:474-82.

65. Shen S, Sun $\mathrm{Q}$, Liang Z, Cui X, Ren X, Chen H, et al. A prognostic model of triple-negative breast cancer based on miR-27b-3p and node status. PLoS ONE. 2014;9:e100664

66. Livak KJ, Schmittgen TD. Analysis of relative gene expression data using real-time quantitative PCR and the 2(-Delta Delta C(T)) Method. Methods. $2001 ; 25: 402-8$

\section{Submit your next manuscript to BioMed Central and take full advantage of:}

- Convenient online submission

- Thorough peer review

- No space constraints or color figure charges

- Immediate publication on acceptance

- Inclusion in PubMed, CAS, Scopus and Google Scholar

- Research which is freely available for redistribution 